\title{
Active Packaging in Food Industry: A Review
}

\author{
Priyanka Prasad*, Anita Kochhar** \\ * Ph.D Student, Department of Food and Nutrition, Punjab Agricultural University Ludhiana, Punjab. \\ ** Professor, Department of Food and Nutrition, Punjab Agricultural University Ludhiana, Punjab.
}

\begin{abstract}
In response to the dynamic changes in current consumer demand and market trends, the area of Active Packaging is becoming increasingly significant. Unlike traditional packaging, which must be totally inert, active packaging is designed to interact with the contents and/or the surrounding environment. Active packaging refers to the incorporation of additives into packaging systems with the aim of maintaining or extending meat product quality and shelf-life. Active packaging systems discussed include oxygen scavengers, ethylene scavengers, flavor and odor absorber/releaser, antimicrobial and antioxidant packaging technologies. Intelligent packaging systems include time-temperature indicators, gas detectors and freshness and/or ripening indicators. Recognition of the benefits of active and intelligent packaging technologies by the food industry and increased consumer acceptance is necessary for commercial realization of these packaging technologies. Advances in nanotechnology will also enable the development of better and new active and intelligent packaging.
\end{abstract}

Key words: Active packaging, Food industry, Intelligent packaging, Shelf life.

\section{Introduction}

Packaging is defined as enclosing food to protect it from tampering or contamination from physical, chemical and biological sources. Packaging maintains the benefits of food processing after the process is complete, enabling foods to travel safely for long distances from their point of origin and still be wholesome at the time of consumption. The primary purpose of food packaging is to protect the food against attack from oxygen, water vapor, ultraviolet light, and both chemical and microbiological contamination. Active packaging as originally described by Labuza and Breene (1989) is used successfully to increase the shelf life of processed foods and meet consumer demands in terms of providing high-quality products that are also fresh and safe. Active Packaging is an innovative concept that can be defined as a mode of packaging in which the package, the product, and the environment interact to prolong shelf life or enhance safety or sensory properties, while maintaining the quality of the product. This is particularly important in the area of fresh and extended shelf-life foods. Intelligent packaging has been defined as packaging 'systems which monitor the condition of packaged foods to give information about the quality of the packaged food during transport and storage' (Ahvenainen, 2003).

Table 1: Examples of active packaging applications for use within the food industry

\begin{tabular}{|l|l|}
\hline Absorbing/scavenging properties & Oxygen, carbon dioxide, moisture, ethylene, flavours, taints, UV light \\
\hline Releasing/emitting properties & Ethanol, carbon dioxide, antioxidants, preservatives, sulphur dioxide, flavours \\
\hline Removing properties & Catalysing food component removal: lactose, cholesterol \\
\hline Temperature control & $\begin{array}{l}\text { Insulating materials, self-heating and self-cooling packaging, temperature-sensitive } \\
\text { packaging }\end{array}$ \\
\hline Microbial and quality control & UV and surface-treated packaging materials \\
\hline
\end{tabular}

It performs some desired functions other than merely providing a barrier to the external environment. At the present time, active and intelligent packaging systems are mainly used in Asia or the United States, whereas in Europe its use is not widespread. The active or intelligent packaging should fulfill following conditions:

a. The materials must be appropriate and effective for their intended use.

b. Materials and articles, including active and intelligent materials and articles, shall be manufactured in compliance with good manufacturing practice

c. The materials must display information about the use or the permitted uses and other relevant information, such as name and quantity of substances released by the active component

d. Mandatory labeling with the words "DO NOT EAT" must be provided to enable consumers to distinguish nonedible parts, when these may be perceived as edible. This information must be visible, legible and indelible. 
Active Packaging In Food Industry: A Review

Table 2: Active packaging and its effect on some foods

\begin{tabular}{|c|c|c|}
\hline Author & Types of Food Package & Results \\
\hline Gomes et al. 2009 & Oxygen Scavenger & Increases shelf life of Cheese Spread \\
\hline Gomez-Estaca et al. 2009 & Antimicrobial & $\begin{array}{l}\text { Antimicrobial activity against Lactobacillus acidophilus, } \\
\text { Pseudomonas fluorescens, Listeria innocua, and Escherichia } \\
\text { coli in Raw fish products and salmon }\end{array}$ \\
\hline Granda-Restrepo et al. 2009 & Antioxidant & Quality improvement in milk powder \\
\hline Gutierrez et al. 2009 & $\begin{array}{l}\text { Odor releaser and } \\
\text { antimicrobial }\end{array}$ & Quality improvement and antimicrobial activity in roast beef \\
\hline Guynot et al. 2003 & Oxygen Scavenger & Increase the shelf life in cakes \\
\hline Mexis et al. 2010 & Oxygen Scavenger & $\begin{array}{l}\text { Quality improvement and increase the shelf life in dark } \\
\text { chocolates }\end{array}$ \\
\hline Moraes et al. 2007 & Antimicrobial & $\begin{array}{l}\text { Antimicrobial activity against filamentous fungi and yeast in } \\
\text { butter }\end{array}$ \\
\hline Baiano et al 2004 & Oxygen scavenger & Inhibition of ascorbic acid degradation in beverages \\
\hline Bailen et al. 2006 & Ethylene scavenger & Reducing the rate of softening in tomatoes \\
\hline de Oliveira et al. 2008 & Antioxidant & Quality improvement of apple slices \\
\hline Zinoviadou et al. 2010 & Antimicrobial & Increase the shelf life in fresh beef \\
\hline Yingyuad et al. 2006 & Antimicrobial & Increase the shelf life in grilled pork \\
\hline Rodríguez et al. 2008 & Antimicrobial & $\begin{array}{l}\text { Antimicrobial activity against Rhizopusstolonifer in Sliced } \\
\text { bread }\end{array}$ \\
\hline
\end{tabular}

\section{Oxygen Scavengers}

\section{Methods Of Active Packaging}

Packaged foods include a certain amount of headspace gases and entrained oxygen. Permeation of oxygen into plastic containers is also of concern. Molecular oxygen $(\mathrm{O} 2)$ can be reduced to a variety of intermediate species by the addition of between one and four electrons thereby forming superoxide, hydroxy radical, hydrogen peroxide, and water. Except water, the remaining three intermediate species are very reactive. These reactive oxygen species are free radical in nature so the oxidative reactions in in which they participate are therefore autocatalytic (Zenner et al 2002). The presence of oxygen, if not desired, may result from inadequate or insufficient evacuation during the packaging process, presence in the food itself or the packaging material and release into the headspace, permeation through the package, introduction of air due to a poor sealing, or micro perforations in the packaging material. A high level of oxygen reduces the nutritional value of food and reduces its shelf life. The oxygen in headspace gases react with sensitive foods in the package and accelerates the deterioration of many food products (Mohan et al 2008) (meats, sausages, milk powder, or spices), degradation of vitamins, and rancidity of oils, nuts, and fatty foods, and also encourages microbial growth. Oxygen in the headspace of food packaging can be removed by vacuum sealing or by inert gas atmosphere in the packaging (N2, CO2), or both. These technologies can remove about 90-95\% of the oxygen present in air from the packed food prior to or during packaging. Such systems are used in packaging orange juice and in the brewing industries, and in modified-atmosphere packaging of food products (Smiddy et al 2002). It is imperative to remove oxygen during packaging, control of the residual oxygen level in the package by use of oxygen absorbent materials limits the rate of deterioration and food spoilage. (Baiano et al 2004, Charls et al 2008, Gomes et al 2009, Mohan et al 2008, Appendini and Hothkiss 2002, Ozdemir and Floros 2004, Suppakul et al 2003) In fresh meat, the presence of oxygen allows oxygenation of myoglobin, which imparts the characteristic red color; since consumers judge meat by its appearance, texture, and flavor, this characteristic of meat is important because (Zerdin et al 2003, Kerry et al 2006). However, high levels of oxygen promote the oxidation of muscle lipids, which eventually has detrimental effects on the color of fresh meat (Grady et al 1998) The shelf-life of meat is increased by decreasing oxygen levels,(Shin et al 2009, Tewari et al 2001) as this prevents growth of fungi and aerobic bacteria (Ozdemir and Floros 2004) Oxygen scavengers reduce and actively control the residual levels of oxygen inside the package, in some cases to $<0.01 \%$ oxygen, which is impossible with other packaging systems (Vermeiren et al 1999).

Oxygen scavengers have the following advantages:

- They prevent oxidation phenomena: rancidification of fats and oils and consequent emergence of off-odors and off-flavors, loss or change of colors characteristic of food, loss of oxygen-sensitive nutrients (vitamins A, C, E, unsaturated fatty acids, etc.) (Lee et al 2010).

- They prevent the growth of aerobic microorganisms.

- They reduce or eliminate the need for preservatives and antioxidants in food by incorporating the added value of "fresh" or "natural."

- They are an economical and efficient alternative to the use of modified atmosphere and vacuum packaging.

- They slow down metabolism of food. 
The use of these systems, either alone or in combination with other traditional packaging systems, and the use of modified atmospheres can therefore extend the commercial life of a food product.

\section{Different mechanisms of action of oxygen scavengers are:}

a.) Oxidation of iron and iron salts: This is the most widely used most effective. Oxygen scavenger systems that are based on iron oxidation reactions are explained by the following equation (Vermeiren et al 2000):

$$
4 \mathrm{Fe}(\mathrm{OH})^{2}+\mathrm{O} 2+2 \mathrm{H} 2 \mathrm{O} \rightarrow 4 \mathrm{Fe}(\mathrm{OH})^{3}
$$

This system is based on the oxidation of iron and ferrous salts (provided in the packet) that react with water provided by food to produce a reaction that moisturizes the iron metal in the product packaging and irreversibly converts it to a stable oxide. The iron powder is contained within small oxygen permeable bags that prevent contact with food.

b.) Oxidation of ascorbic acid and unsaturated fatty acids (oleic, linoleic).

c.) Oxidation of photosensitive coloring matter.

d.) Enzymatic oxidation by Glucose oxidase (Vermeiren et al 2000)

These methods can reduce oxygen levels to $<0.01 \%$, which is much lower than the typical level of $0.3-3.0 \%$ obtained with residual oxygen-modified atmosphere packaging (Sen et al 2012). This lower level of oxygen can be maintained for long periods depending upon the oxygen permeability of the packaging material.

The disadvantages of sachets is the need for additional packaging operations to add the sachet to each package, also they cannot be used in beverages or foods containing high levels of water because they become inactive when wet (Day 2008). Also in high moisture foods aqueous slurry of oxygen absorbent is formed when moisture enters in the adsorbent packet. The aqueous slurry oozes out of the package on to the foodstuff, spoiling its appearance (Yeh et al 2008). In contrast, ascorbic acid can be used in liquid food or beverage as an efficient oxygen scavenger.

\section{Commercial presentations of oxygen scavengers are:}

i.) Independent systems such as bags, strips, or labels, which are incorporated into or attached to the inside of the package, but are separate elements. They are the most widely used systems.

ii.) Systems integrated into the packaging material itself, not visually perceptible as distinct elements. Iron, ascorbic acid, and low-molecular-weight ingredients are used in this way (Poubol and Izumi 2005).

Selection of oxygen scavenger (shape, size, ability to absorb oxygen, time to reach equilibrium) must be very strict and tailored to the needs and characteristics of each food (liquid, solid, dry, fat, water content, activity water, etc.) and storage temperature (Tewari et al 2002). Fruits and vegetables, seafood, cheeses, baked goods, pastries, cookies, pizza crusts, and pasta can benefit from packaging systems with both oxygen absorption and antimicrobial release systems (Suppakul et al 2003).

\section{Carbon Dioxide Generating System}

Carbon dioxide suppresses microbial activity. Relatively high $\mathrm{CO}_{2}$ levels (60 to 80\%) inhibit microbial growth on surfaces and, in turn, prolong shelf life of packed food. Therefore, a complementary approach to O2 scavenging is the impregnation of a packaging structure with a $\mathrm{CO} 2$ generating system or the addition of the latter in the form of a sachet (Ha et al 2001). Since the permeability of CO2 is 3 to 5 times higher than that of $\mathrm{O} 2$ in most plastic films, it must be continuously produced to maintain the desired concentration within the package. High $\mathrm{CO} 2$ levels cause changes in taste of products so a $\mathrm{CO} 2$ generator is only useful in certain applications such as fresh meat, poultry, fish and cheese packaging. oxygen-free environment alone is insufficient to retard the growth of Staphylococcus aureus, Vibrio species, Escherichia coli, Bacillus cereus and Enterococcus faecalis at ambient temperatures. $\mathrm{O} 2$ and $\mathrm{CO} 2$ absorber inhibited the growth of Clostridium sporogenes (Scannell et al 2000).

\section{Ethylene Scavengers}

The control of ethylene in stored conditions plays a key role in prolonging the postharvest life of many types of fresh produce (Terry et al 2007). Most fruits and vegetables release ethylene after they are harvested. Ethylene is a phytohormone that initiates and accelerates ripening, produces softening and degradation of chlorophylls, and inevitably leads to deterioration of fresh or minimally processed fruits and vegetables. Ethylene scavengers are useful for preserving ethylene-sensitive fruits and vegetables such as apples, bananas, mangos, tomatoes, onions, carrots.

\section{Mechanism of Action:}

a.) One of the main mechanisms of action of ethylene scavengers is based on the use of potassium permanganate, which oxidizes ethylene to carbon dioxide and water. The typical permanganate content is 
between $4 \%$ and $6 \%$ (Abe and Watada 1991). Potassium permanganate oxidizes ethylene and changes color from purple to brown, and thus, a color change indicates its residual ethylene absorbing capacity, but because of its toxicity potassium permanganate cannot be used in direct contact with food.

b.) Other systems are based on the ability of certain materials to absorb ethylene, alone or with any oxidizing agent. For example, palladium has been shown to have a higher ethylene adsorption capacity than permanganate-based scavengers in situations of high relative humidity (Smith et al 2009).

LDPE and HDPE polyethylene films as packaging material are able to absorb ethylene; ethanol, ethyl acetate, ammonia, and hydrogen sulfide are used in food industry. These films keep food fresh for longer and eliminate odors.

\section{Flavor and Odor Absorber/Releaser}

Addition of essences and odors can increase the desirability of the food to the consumer, to improve the aroma of fresh product itself, or to enhance the flavor of food when the package is opened. These flavors and aromas are released slowly and evenly in the packaged product during its shelf life or release can be controlled to occur during opening the package or food preparation. Gradual release of odors can offset the natural loss of taste or smell of products with long shelf lives (Almenar et al 2009).

\section{Antimicrobials}

Microbiological contamination due to pathogenic or spoilage bacteria may occur during inadequate processing, or when package integrity is compromised due to a ruptured seal, puncture, dents, or incomplete glass finishes (Cutter 2002). Traditional methods of preserving food from the damaging effects of microbial growth include heat treatment, drying, freezing, refrigeration, irradiation, modified-atmosphere packaging, and addition of salts or antimicrobial agents. Antimicrobial packaging include systems such as adding a sachet into the package, dispersing bioactive agents in the packaging, coating bioactive agents on the surface of the packaging material, or utilizing antimicrobial macromolecules with film-forming properties or edible matrices (Coma 2008). A large number of agents with antimicrobial properties (ethanol, carbon dioxide, silver ions, chlorine dioxide, antibiotics, organic acids, essential oils and spices, etc.) are being used for the purpose of inhibiting the growth of microorganisms that can lead to deterioration of foodstuffs (bacteria can also attack the packages affecting their functions and properties).

Packaging systems that release volatile antimicrobials also include chlorine dioxide, plant extracts, sulfur dioxide, essential oils (Skandamis and Nychas 2002, Rodriguez et al 2007, Lopez et al 2007), carbon dioxide, and allylisothiocyanate (Pires et al 2009, Winther and Nielsen 2006, Plackett et al 2007) release systems. The theoretical advantage of volatile antimicrobials is that they can penetrate most of the food matrix and the polymer not necessarily in direct contact with food. This type of active packaging is suitable for applications where contact between the portions of food and packaging does not occur, as in the case of ground beef (Appendini and Hothkiss 2002, Nadarajah et al 2005).

Chlorine dioxide can exist in gaseous, liquid, or solid form. It has proven effective not only against bacteria and fungi but also against viruses. Potential applications of chlorine dioxide include meat, poultry, fish, dairy products, and confectionery and baked goods (Coma 2008).

Sulfur dioxide is the most effective material for controlling decomposition of grapes and is much more effective than the combination of $\gamma$-radiation and heat. However, it has drawbacks that include bleaching of grape skin and the fact that some sulfur dioxide may remain on grapes.

The role of carbon dioxide in the packaging atmosphere is to suppress microbial growth (Kerry et al 2006) and to slow down the rate of respiration of fruits and vegetables. Because the permeability of carbon dioxide is between 3 and 5 times that of oxygen in most packaging films, carbon dioxide must be continuously released to maintain the desired concentration in the package (Ozdemir and Floros 2004) High levels of carbon dioxide $(10-80 \%)$ are suitable for foods such as meat and poultry in order to inhibit microbial growth on the surface of the products and to extend the shelf life (Nerín et al 2006)

Another way of tackling the problem of microbial growth is by the use of nonvolatile antimicrobial additives. Many preservatives (sorbic acid, benzoic acid, propionic acid and its salts, or bacteriocins such as nisin, natural spices, silver ions, chelators, etc.) are added to plastic films and materials used as antimicrobials. But these nonvolatile antibacterial require direct contact with the food to be active (Ouattara et al 2000).

\section{Antioxidants}

Oxidation of fats is one of the most important mechanisms leading to food spoilage, second only to growth of microorganisms. The oxidation of lipids in food leads to a reduction in shelf-life due to changes in taste and/or odor, deterioration of the texture and functionality of muscle foods, and a reduction in nutritional quality (Pereira et al 2010). Oxidation of food can be avoided by use of oxygen scavengers and antioxidant agents in the packaging. Such packaging is intended to prevent or slow down the oxidation reactions that affect the 
quality of food (Pereira et al 2010). However, radicals, mainly oxo, hydroxyl, and superoxide, are originated from oxygen and they are the main initiators of oxidation. Thus, oxidation can be avoided by eliminating radicals as soon as they are formed.

A varnish with natural antioxidant of rosemary extract, which acts as a radical scavenger either in the vapor phase or by direct contact, can eliminate or delay the oxidation of foods inside the food package. This eliminates the need to add antioxidants to the package or the food (Nerin et al 2008) The use of antioxidant active film in the conservation of fresh meat can enhance the stability of myoglobin and fresh meat against oxidation processes. Migration of $\alpha$ tocopherol from a multilayer active packaging (made of high-density polyethylene, ethylene vinyl alcohol, and a layer of low-density polyethylene containing the antioxidant $\alpha$-tocopherol) shows a delay in lipid oxidation in whole milk powder (Nerin et al 2006).

The antioxidant content decreases during storage due to diffusion of the antioxidant through the film and its subsequent evaporation at the surface. This decrease in the concentration of the antioxidant can be prevented by adding an extra layer of film. Antioxidants can be used for oil, nuts, butter, fresh meat, meat derivatives, bakery products, fruits and vegetables.

\section{Intelligent Packaging}

The headspace of food packages undergoes changes in their composition over time. Devices capable for identifying, quantifying, and/or reporting changes in the atmosphere within the package, the temperatures during transfer and storage and the microbiological quality of food are the basis of intelligent packaging. The indicators should be easily activated and exhibit a change (or show an indication) that is easily measurable and irreversible, time- and temperature-dependent changes must be reproducible and ideally matched or readily correlated with the food quality, and also provide information regarding the status of the package (Yam et al 2005).

\section{i.) Time-Temperature Indicators}

They are of two types: visual indicators and radio frequency identification (RFID) tag.

The visual indicators change color in response to cumulative exposure to temperature. The main mechanisms of action include enzymatic reactions, polymerization, or chemical diffusion. These products are used to monitor exposure to unsuitable temperatures during transport and storage and are an indication of quality for the producer because they ensure that the product reaches the consumer in optimal conditions (Welt et al 2003).

The RFID tag is an advanced form of data carrier for automatic product identification and traceability. In an RFID system, a reader emits radio waves to capture data from an RFID tag, and the data are then passed to a host computer for analysis and decision making. The RFID tag contains a minuscule microchip connected to a tiny antenna.

\section{ii.) Seal and Leak Indicators}

The gas composition in the package headspace often changes as a result of the activity of the food product, leaks, nature of the package, or environmental conditions. $\mathrm{O}_{2}$ and $\mathrm{CO}_{2}$ can be used to monitor food quality, as seal indicators (leaks), or to verify the effectiveness of an oxygen absorber. Most $\mathrm{O}_{2}$ or $\mathrm{CO}_{2}$ indicators change color as a result of chemical or enzymatic reactions. A color change indicates when the oxygen concentration exceeds the limit established in a sealed food package (Hu et al 2009).

A major problem with such indicators is that they require storage under anaerobic conditions, since they quickly deteriorate in air (Huang et al 2009).

\section{iii.) Freshness and/or Ripening Indicators}

Freshness and/or ripening indicators provide an indication of the deterioration or loss of freshness of packaged goods. They are described as indicating different mechanisms of volatile metabolites, such as diacetyl, amines, carbon dioxide, (Nopwinyuwong et al 2010) ammonia and hydrogen sulfide, produced during the aging of foods (Smolander et al 2002).

Changes in the concentration of hydrogen sulfide or organic acids such as $n$-butyrate, L-lactic, D-lactate, and acetic acid during storage are offered as viable indicators of the formation of metabolites in meat products, fruits, and vegetables (Wanihsuksombat et al 2010). Indicators based on color changes due to changes in $\mathrm{pH}$ are of great potential use as indicators of microbial metabolites and ripeness (Rokka et al 2004, Hong and Park 2000).

Products formed during microbial growth (carbon dioxide and hydrogen sulfide) and biogenic amines are of great potential use in indicating the freshness of meat and fish (Kerry et al 2006, Smolander et al 2002). Biogenic amines (putrescine, cadaverine, histamine, and others) are formed by degradation of protein-containing food to amino. Thus, biogenic amines are an indicator of food deterioration and only an indirect indicator of food freshness in meat (Rokka et al 2004) and fish (Pacquit et al 2006, Pacquit et al 2007). 


\section{Conclusion}

The package as a simple instrument for the marketing of food is changing to match the needs of consumers and the food industry. In order to address the present imbalance between potential and realization of intelligent packaging concepts, a number of research gaps need to be filled. New types of active and intelligent packaging have been and will be developed to meet these needs. Apart from aspects of quality, safety, and distribution already outlined, intelligent packaging offers considerable potential as a marketing tool. The correct use of one or more types of active or intelligent packaging will increase the shelf-life and food safety. However, the development and implementation of this type of packaging will depend on the acceptance and costeffectiveness for industry and consumers.

\section{References:}

[1]. Abe, K. and Watada, A. Ethylene absorbent to maintain quality of lightly processed fruits and vegetables. J. Food Sci. 1991, 56, 1589-1592.

[2]. Ahvenainen, R. Active and intelligent packaging: an introduction. 2008, Cambridge, UK: Woodhead Publishing Ltd.

[3]. Almenar, E., Catala, R., Hernandez-Munoz, P. and Gavara, R. Optimization of an active package for wild strawberries based on the release of 2-nonanone. Lwt-Food Sci. Technol. 2009, 42, 587-593.

[4]. Appendini, P. and Hotchkiss, J.H. Review of antimicrobial food packaging. Innov. Food Sci. Emerg. 2002, 3, 113-126.

[5]. Baiano, A., Marchitelli, V., Tamagnone, R. and Del Nobile, M.A. Use of active packaging for increasing ascorbic acid retention in food beverages. J. Food Sci. 2004, 69, 502-508.

[6]. Bailen, G., Guillen, F., Castillo, S., Serrano, M., Valero, D. and Martinez-Romero, D. Use of activated carbon inside modified atmosphere packages to maintain tomato fruit quality during cold storage. J. Agric. Food Chem. 2006, 54, 2229-2235.

[7]. Charles, F., Guillaume, C. and Gontard, N. Effect of passive and active modified atmosphere packaging on quality changes of fresh endives. Postharvest Biol. Technol. 2008, 48, 22-29.

[8]. Coma, V. Bioactive packaging technologies for extended shelf life of meat-based products. Meat Sci. 2008, 78, 90-103

[9]. Cutter, C.N. Microbial control by packaging: A review. Crit. Rev. Food Sci. Nutr. 2002, 42, 151-161.

[10]. Day, B. Active Packaging of Food. In Smart Packaging Technologies for Fast Moving Consumer Goods; John Wiley \& Sons: Chichester, UK, 2008; pp 1-18

[11]. de Oliveira, T.M., Soares, N.F., de Paula, C.D. and Viana, G.A. Active packaging use to inhibit enzymatic browning of apples. Semin. Cienc. Agrar. 2008, 29, 117-128.

[12]. Gomes, C., Castell-Perez, M.E., Chimbombi, E., Barros, F., Sun, D., Liu, J., Sue, H.J., Sherman, P., Dunne, P. and Wright, A.O. Effect of Oxygen-absorbing packaging on the shelf life of a liquid-based component of military operational rations. J. Food Sci. $2009,74,167-176$.

[13]. Gomes, C., Castell-Perez, M.E., Chimbombi, E., Barros, F., Sun, D., Liu, J., Sue, H.J., Sherman, P., Dunne, P. and Wright, A.O. Effect of Oxygen-absorbing packaging on the shelf life of a liquid-based component of military operational rations. J. Food Sci. $2009,74,167-176$.

[14]. Gomez-Estaca, J., De Lacey, A.L., Gomez-Guillien, M.C., Lopez-Caballero, M.E. and Montero, P. Antimicrobial activity of composite edible films based on fish gelatin and chitosan incorporated with clove essential oil. J. Aquat. Food Prod. Tech., 2009, 18, 46-52.

[15]. Grady, M.N., Monahan, F.J., Bailey, J., Allen, P., Buckley, D.J. and Keane, M.G. Colourstabilising effect of muscle vitamin e in minced beef stored in high oxygen packs. Meat Sci. 1998, 50, 73-80.

[16]. Granda-Restrepo, D.M., Soto-Valdez, H., Peralta, E., Troncoso-Rojas, R., Vallejo-Cordoba, B., Gamez-Meza, N. and Graciano-Verdugo, A.Z. Migration of alpha-tocopherol from an active multilayer film into whole milk powder. Food Res. Int., 2009, 42, $1396-1402$.

[17]. Gutierrez, L., Escudero, A., Batlle, R. and Nerin, C. Effect of mixed antimicrobial agents and flavors in active packaging films. J. Agric. Food Chem., 2009, 57, 8564-8571.

[18]. Guynot, M.E., Sanchis, V., Ramos, A.J. and Marin, S. Mold-free shelf-life extension of bakery products by active packaging. J. Food Sci., 2003, 68, 2547-2552.

[19]. Ha, J.U., Kim, Y.M. and Lee, D.S. Multilayered antimicrobial polyethylene films applied to the packaging of ground beef. Packag Technol Sci. 2001, 14, 55-62.

[20]. Hong, S. and Park,W. Use of color indicators as an active packaging system for evaluating kimchi fermentation. J. Food Eng. 2000, 46, 6772.

[21]. Hu, C.T., Liu, C.K., Huang, M.W., Syue, S.H., Wu, J.M., Chang, Y.S., Yeh, J.W. and Shih, H.C. Plasma-enhanced chemical vapor deposition carbon nanotubes for ethanol gas sensors. Diam. Relat. Mater. 2009, 18, 472-477.

[22]. Huang, C.S., Yeh, C.Y., Yuan, C.H., Huang, B.R. and Hsiao, C.H. The study of a carbon nanotube O2 sensor by field emission treatment. Diam. Relat. Mater. 2009, 18, 461-464.

[23]. Kerry, J.P., O'Grady, M.N. and Hogan, S.A. Past, current and potential utilisation of active and intelligent packaging systems for meat and muscle-based products: A review. Meat Sci. 2006, 74, 113-130.

[24]. Labuza, T P and Breene W M. Applications of active packaging for improvement of shelf-life and nutritional quality of fresh and extended shelf-life foods. J Food Proc Preserv, 2008, 45, 1-69.

[25]. Lee, D.S., Yam, K.L. and Piergiovanni, L. Active and Intelligent packaging. Food Packaging Sci. Technol.. $2010,1,445$ - 473.

[26]. López, P., Sánchez, C., Batlle, R. and Nerín, C. Development of flexible antimicrobial films using essential oils as active agents. J. Agric. Food Chem. 2007, 55, 8814-8824.

[27]. Mexis, S.F., Badeka, A.V. and Kontominas, M.G. Quality evaluation of raw ground almond kernels (Prunus dulcis): Effect of active and modified atmosphere packaging, container oxygen barrier and storage conditions. Innov. Food Sci. Emerg. 2009, 10, 580-589.

[28]. Mohan, C., Ravishankar, C. N. and Srinivasagopal, T. K. Effect of O2 scavenger on the shelf-life of catfish (Pangasius sutchi) steaks during chilled storage. J. Sci. Food Agric. 2008, 88, 442-448.

[29]. Moraes, A.R., Gouvela, L.R., Soares, N.F., Santos, M.D. and Goncalvesi, M.C. Development and evaluation of antimicrobial film on butter conservation. Ciencia Tecnol. Alime. 2007, 27, 33-36.

[30]. Nadarajah, D., Han, J.H. and Holley, R.A. Inactivation of Escherichia coli O157:H7 in packaged ground beef by allyl isothiocyanate. Int. J. Food Microbiol. 2005, 99, 269-279.

[31]. Nerín C., Tovar, L., Djeane, D., Camo, J., Salafranca, J., Beltrán J. and Roncalés, P. Stabilization of beef meat by a new active packaging containing natural antioxidants. J. Agric. Food Chem. 2006, 54, 7840-7846.

[32]. Nerin, C., Tovar, L. and Salafranca, J. Behaviour of a new antioxidant active film versus oxidizable model compounds. J. Food Eng. 2008, 84, 313-320.

[33]. Nopwinyuwong, A., Trevanich, S. and Suppakul, P. Development of a novel colorimetric indicator label for monitoring frehness of intermediate-moisture dessert spoilage. Talanta, 2010, 81, 1126-1132.

[34]. Ouattara, B., Simard, R. E., Piette, G., Be'gin, A., and Holley, R. A. Inhibition of surface spoilage bacteria in processed meats by application of antimicrobial films prepared with Chitosan. Int. J. Food Microbiol., 2000, 62, 139-148.

[35]. Ozdemir,M. and Floros, J.D. Active food packaging technologies. Crit. Rev. Food Sci. Nutr. 2004, 44, $185-193$. 
[36]. Pacquit, A., Frisby, J., Diamond, D., Lau, K.T., Farrell, A.P., Quilty, B. and Diamond, D. Development of a smart packaging for the monitoring of fish spoilage. Food Chem. 2007, 102, 466-470.

[37]. Pacquit, A., Lau, K.T., McLaughlin, H., Frisby, J., Quilty, B. and Diamond, D. Development of a volatile amine sensor for the monitoring of fish spoilage. Talanta, 2006, 69, 515-520.

[38]. Pereira de Abreu, D.A., Paseiro, P., Maroto, J. and Cruz, J.M. Evaluation of the effectiveness of a new active packaging film containing natural antioxidants (from barley husks) that retard lipid damage in frozen Atlantic salmon (Salmo salar L.). Food Res. Int. 2010, 43, 12771282 .

[39]. Pereira deAbreu, D., Losada, P.P., Maroto, J. and Cruz, J.M. Lipid damage during frozen storage of Atlantic halibut (Hippoglossus hippoglossus) fillets packaged with an active packaging film containing antioxidants. Food Chem. 2010, 126, 315-320.

[40]. Pires, A.D., Soares, N.F., de Andrade, N.J., da Silva, L.M., Camilloto, G.P. and Bernardes, P.C. Increased preservation of sliced mozzarella cheese by antimicrobial sachet incorporated with allyl isothiocyanate. Braz. J. Microbiol. 2009, 40, 1002-1008.

[41]. Plackett, D., Ghanbari-Siahkali, A. and Szente, L. Behavior of alpha- and beta-cyclodextrinencapsulated allyl isothiocyanate as slow-release additives in polylactide-co-polycaprolactone films. J. Appl. Polym. Sci. 2007, 105, 2850-2857.

[42]. Poubol, J. and Izumi, H. (2005). Physiology and microbiological quality of fresh-cut mango cubes as affected by high-O2 controlled atmospheres. J. Food Sci., 2005, 70, 286 - 291.

[43]. Rodriguez, A., Batlle, R. and Nerin, C. The use of natural essential oils as antimicrobial solutions in paper packaging. Prog. Org. Coat. 2007, $60,33-38$.

[44]. Rodríguez, A., Nerin, C. and Batlle, R. New cinnamon-based active paper packaging against Rhizopusstolonifer food spoilage. J. Agric. Food Chem. 2008, 56, 6364-6369.

[45]. Rokka, M.. Eerola, S., Smolander, M., Alakomi, H. and Ahvenainen, R. Monitoring of the quality of modified atmosphere packaged broiler chicken cuts stored in different temperature conditions B. Biogenic amines as quality-indicating metabolites. Food Control, 2004, 15, 601607.

[46]. Scannell, A.M., Hill, C., Ross, R. P., Marx, S., Hartmeier, W., and Arendt, E. K. Development of bioactive food packaging materials using immobilized bacteriocins Lacticin 3147 and Nisaplin. Int. J. Food Microbiol. 2000, 60, 241-249.

[47]. Sen, C., Mishra, H.N. and Srivastav, P.P. Modified atmosphere packaging and active packaging of banana (Musa spp.): A review on control of ripening and extension of shelf life. J. Stored Products Postharvest Res.2012, 39, 122-132.

[48]. Shin, Y., Shin, J and Lee, Y. Effects of oxygen scavenging package on the quality changes of processed meatball product. Food Sci. Biotechnol. 2009, 18, 73-78.

[49]. Skandamis, P.N. and Nychas, G.E. Preservation of fresh meat with active and modified atmosphere packaging conditions. Int. J. Food Microbiol. 2002, 79, 35-45.

[50]. Smiddy, M., Fitzgerald, M., Kerry, J. P., Papkovsky D .B., O’Sullivan C. K., and Guilbault G G). Use of oxygen sensors to nondestructively measure the oxygen content in modified atmosphere and vacuum packed beef: impact of oxygen content on lipid oxidation. Meat Science, 2002, 61, 285-290

[51]. Smith, A.J., Poulston, S., Rowsell, L., Terry, L.A. and Anderson, J.A. A New palladium-based ethylene scavenger to control ethylene-induced ripening of climacteric fruit. Platin. Met. Rev. 2009, 53, 112-122.

[52]. Smolander, M., Hurme, E., Latva-Kala, K., Louma, T., Alakomi, H. and Ahvenainen, R. Myoglobin-based indicators for the evaluation of freshness of unmarinated broiler cuts. Innov. Food Sci. Emerg. 2002, 3, 279-288.

[53]. Suppakul, P., Miltz, J., Sonneveld, K. and Bigger, S.W. Active packaging technologies with an emphasis on antimicrobial packaging and its applications. J. Food Sci. 2003, 68, 408-420.

[54]. Terry, L.A., Ilkenhans, T., Poulston, S., Rowsell, L. and Smith, A.J. Development of new palladium-promoted ethylene scavenger. Postharvest Biol. Technol. 2007, 45, 214-220.

[55]. Tewari, G., Jayas, D.S., Jeremiah, L.E. and Holley, R.A. Absorption kinetics of oxygen scavengers. Int. J. Food Sci. Technol. 2002, 37, 209217.

[56]. Tewari, G., Jayas, D.S., Jeremiah, L.E. and Holley, R.A. Prevention of transient discoloration of 2001beef. J. Food Sci. 2001, 66, 506-510.

[57]. Vermeiren, L., Devlieghere, F., van Beest, M., de Kruijf, N. and Debever, J. Developments in the active packaging of foods. Trends Food Sci. Technol. 1999, 10, 77-86.

[58]. Vermeiren, L., Devlieghere, F., van Beest, M., de Kruijf, N. and Debever, J. Developments in the active packaging of foods. J. Food Technol. Afra. 2000, 5, 6-13.

[59]. Wanihsuksombat, C., Hongtrakul, V. and Suppakul, P. Development and characterization of a prototype of a lactic acid-based timetemperature indicator for monitoring food product quality. J. Food Eng. 2010, 100, 427-434.

[60]. Welt, B. A., Sage, D. S. and Berger, K. L. Performance specification of time-temperature integrators designed to protect against botulism in refrigerated fresh foods. J. Food Sci. 2003, 68, 2-9.

[61]. Winther, M., and Nielsen, P.V. Active packaging of cheese with allyl isothiocyanate, an alternative to modified atmosphere packaging. $J$. Food Protect. 2006, 69, 2430-2435.

[62]. Yam, K. L., Takhistov, P. T. and Miltz, J. Intelligent packaging: concepts and applications. J. Food Sci., 2005, 70, 1-10.

[63]. Yeh, J.T., Cui, L., Chang, C.J., Jiang, T. and Chen, K.N. Investigation of the oxygen depletion properties of novel oxygen-scavenging plastics. J. Appl. Polym. Sci. 2008, 110, 1420-1434.

[64]. Yingyuad, S., Ruamsin, S., Reekprkhon, D., Douglas, S., Pongamphai, S. and Siripatrawan, U. Effect of chitosan coating and vacuum packaging on the quality of refrigerated grilled pork. Packag. Technol. Sci. 2006, 19, 149-157.

[65]. Zenner B.D. and Benedict, C.S. Polymer compositions containing oxygen scavenging compounds. United States Patent, 6391406, 5/21/2002

[66]. Zerdin, K., Rooney, M.L. and Vermue, J. The vitamin C content of orange juice packed in an oxygen scavenger material. Food Chem. 2003, $82,387-395$.

[67]. Zinoviadou, K.G., Koutsoumanis, K.P. and Biliaderis, C.G. Physical and thermo-mechanical properties of whey protein isolate films containing antimicrobials, and their effect against spoilage flora of fresh beef. Food Hydrocolloids, 2010, 24, 49-59. 